\title{
Three Dimensional Interface Finite Element Derivation and Application
}

\author{
Wenshan Lin ${ }^{*}$ \\ Department of Architecture, China University of Science and Technology, \\ No.245, Sec. 3, Academia Rd., Nangang Dist., Taipei City 115, Taiwan (R.O.C.) \\ *Corresponding author
}

\begin{abstract}
In the present study, the special interface element has been derived. And that develop three-dimensional nonlinear finite element model depicting the global behavior for RC structure strengthened by steel plates up to failure. The interface element captures not only the shear and normal stress concentration, but can also judge separation if the peak shear and normal stress are exceeded. The finite element solution reveals a close correlation to the experimental data available for RC structures strengthened by steel plates.
\end{abstract}

Keywords-interface element; finite element; RC structure

\section{INTRODUCTION}

RC structures must be repaired or strengthened when their behavior is found to be inadequate. The inadequacy may be due to inferior materials, poor design, or a constructional fault. Deteriorated RC structures need to be repaired to extend their useful service life. Strengthening and repair of RC members using steel plates externally bonded to the tension face of the members is one technique that has been studied by many investigators [1,2], and many structures have been successfully strengthened in terms of flexure using this technique $[3,4]$. The successfully strengthened structures must retain full composite action until ductile failure. The peak shear and normal stress are developed at the plate curtailment under the loading, and the plate separation fails immediately if the peak shear and normal stress exceed the strength of the interface. Researchers [5 7] in general concluded that shear and normal stress concentrations at the plate cut-off point are the main reasons causing end peeling. A two-dimensional nonlinear finite element analysis of an RC beam strengthened by plates has been studied to focus on the normal and shear stress concentrations at the plate cut-off $[8,9]$. In order to provide extra shear or torsion for deficient RC beams, lateral steel plates are usually attached. For this purpose, a nonlinear finite element analysis must extend to a three-dimensional analysis. At present, few existing analytical or numerical threedimensional nonlinear models have attempted to study RC structures strengthened with steel plates. In the present study, the special interface element has been derived. And the nonlinear finite element model depicting the global behavior of externally reinforced RC structures up to the point of failure is developed.

\section{THREE DiMENSIONAL INTERFACE ELEMENT MODEL}

The concrete / glue / plate interface element model used a sixteen node thin interface element. The sixteen nodes thin interface element was derived from 2D (six-node thin interface element by Ziraba [9]) and extended to 3D by the author. The formulation of a new thin interface three-dimensional element was developed as the failure mechanisms for RC beams strengthened with an external steel plate on the lateral or tensile side. Since the glue thickness is much smaller than the other components of the plate bonded beam, a sixteen nodes thin interface element, as shown in Figure 1, was deemed sufficient to represent the interface element. After defining the equivalent pseudo node from $1^{\prime}$ to 8 ' as shown in Figure 1, an isoparametric formulation with parabolic shape functions was adopted. A $3 \times 3$ point Gaussian integration rule was used for this element. The displacements $\mathrm{u}, \mathrm{v}$ and $\mathrm{w}$ were each interpolated from equivalent pseudo eight nodal values using a shape function $N_{i}$ as

$$
u=\sum_{i=1}^{8} N_{i} \bar{u}_{i} \quad v=\sum_{i=1}^{8} N_{i} \bar{v}_{i} \quad w=\sum_{i=1}^{8} N_{i} \bar{w}_{i}
$$

where $N_{i}=N_{i}(\xi, \eta)$ are the shape functions at the eight equivalent nodal points from $1^{\prime}$ to $8^{\prime}$, and $\bar{u}_{i}, \bar{v}_{i}$ and $\bar{w}_{i}$ are the average nodal displacements along line $z=0$. Thus, the strain $\varepsilon_{X}$ along the x-direction can be approximated as

$$
\varepsilon_{x}=\frac{\partial u}{\partial x}=\frac{\partial}{\partial x} \sum_{i=1}^{8} N_{i} \bar{u}_{i}=\sum_{i=1}^{8} \frac{\partial N_{i}}{\partial x} \bar{u}_{i}=\sum_{i=1}^{8} \frac{\partial N_{i}}{\partial x}\left(\frac{u_{i}+u_{i+8}}{2}\right)
$$

Similarly, the strain $\varepsilon_{y}$ and $\varepsilon_{z}$ along the y-direction and z-direction can be approximated as

$$
\begin{gathered}
\varepsilon_{y}=\frac{\partial v}{\partial y}=\frac{\partial}{\partial y} \sum_{i=1}^{8} N_{i} \bar{v}_{i}=\sum_{i=1}^{8} \frac{\partial N_{i}}{\partial x} \bar{v}_{i}=\sum_{i=1}^{8} \frac{\partial N_{i}}{\partial y}\left(\frac{v_{i}+v_{i+8}}{2}\right) \\
\varepsilon_{z}=\varepsilon_{n}=\frac{\partial w}{\partial n}=\sum_{i=1}^{8} N_{i}\left(\frac{\partial w}{\partial n}\right)_{i}=\sum_{i=1}^{8} N_{i} \frac{w_{i+8}-w_{i}}{t}
\end{gathered}
$$

where $\mathrm{t}$ is the element thickness. The shear strain $\gamma_{x y}, \gamma_{y z}$ and $\gamma_{z x}$ are approximated as

$$
\gamma_{x y}=\frac{\partial u}{\partial y}+\frac{\partial v}{\partial x}=\sum_{i=1}^{8} \frac{\partial N_{i}}{\partial y}\left(\frac{u_{i}+u_{i+8}}{2}\right)+\sum_{i=1}^{8} \frac{\partial N_{i}}{\partial x}\left(\frac{v_{i}+v_{i+8}}{2}\right)
$$




$$
\begin{aligned}
& \gamma_{y z}=\frac{\partial v}{\partial z}+\frac{\partial w}{\partial y}=\sum_{i=1}^{8} N_{i} \frac{v_{i+8}-v_{i}}{t}+\sum_{i=1}^{8} \frac{\partial N_{i}}{\partial y}\left(\frac{w_{i}+w_{i+8}}{2}\right) \\
& \gamma_{z x}=\frac{\partial u}{\partial z}+\frac{\partial w}{\partial x}=\sum_{i=1}^{8} N_{i} \frac{u_{i+8}-u_{i}}{t}+\sum_{i=1}^{8} \frac{\partial N_{i}}{\partial x}\left(\frac{w_{i}+w_{i+8}}{2}\right)
\end{aligned}
$$

The strain vector in three-dimensional element with not geometrical nonlinear results in

$$
\begin{aligned}
\{\varepsilon\} & =[B]\{\delta\} \\
& =\left[\begin{array}{lllll}
B_{1} & B_{2} & \cdots \cdots & B_{15} & B_{16}
\end{array}\right]\{\delta\}
\end{aligned}
$$

where $[B]$ is the strain matrix form as

$$
\left[B_{i}\right]=\left[\begin{array}{ccc}
\frac{1}{2} \frac{\partial N_{i}}{\partial x} & 0 & 0 \\
0 & \frac{1}{2} \frac{\partial N_{i}}{\partial y} & 0 \\
0 & 0 & -\frac{N_{i}}{t} \\
\frac{1}{2} \frac{\partial N_{i}}{\partial y} & \frac{1}{2} \frac{\partial N_{i}}{\partial x} & 0 \\
0 & -\frac{N_{i}}{t} & \frac{1}{2} \frac{\partial N_{i}}{\partial y} \\
-\frac{N_{i}}{t} & 0 & \frac{1}{2} \frac{\partial N_{i}}{\partial x}
\end{array}\right] \quad i=1 \sim 8
$$

The stiffness $\mathrm{k}_{\mathrm{ij}}$ in the local coordinate is evaluated as

$$
\begin{aligned}
k_{i j} & =\iiint[B]_{i}^{T}[D]_{L O}[B]_{j} d V \\
& =\int_{-1}^{1} \int_{-1}^{1} M_{i j} d \xi d \eta
\end{aligned}
$$

The $3 \times 3$ Gauss point integration rule is used and the equation becomes

$$
k_{i j}=\sum_{p=1}^{3} \sum_{q=1}^{3} M_{i j} W_{p} W_{q}
$$

Then, the element stiffness matrix in the local coordinate has to be transformed to the global coordinate system.

\section{OTHER FINITE ELEMENT MODEL}

Concrete and external plates are represented by a twentynode isoparameter finite element as shown in Figure 2. Numerical integration for all elements was carried out using Gauss-integration technique over $3 \times 3 \times 3$ sampling points. During every loading level iteration, the material matrix at every sampling point of the concrete and external plates was updated and modified to take into account the nonlinear material. The internal steel, including the main tensile and compressive steel as well as the stirrups, was modeled using a two nodes truss element.

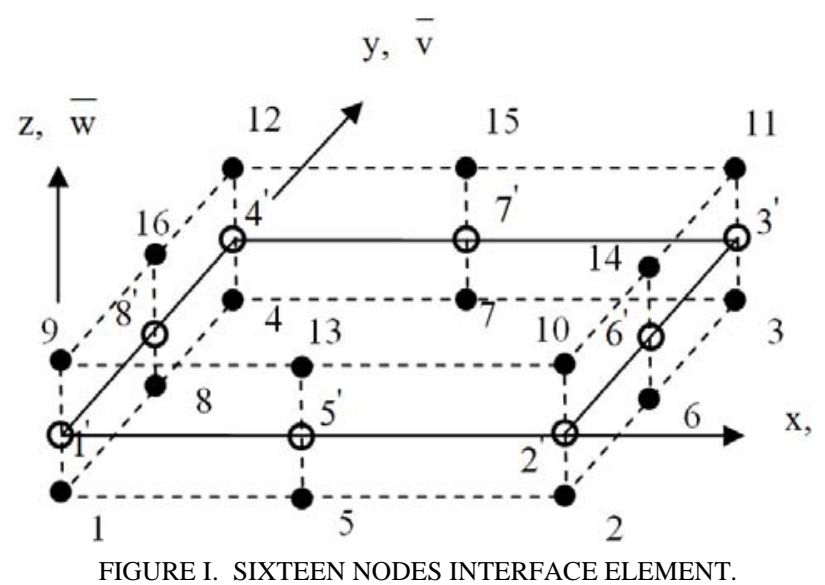

IV. MATERIAl MODEL

\section{A. Material Model for Interface}

The interface material was modeled by a linear-elasticfracture relationship. Prior to the cracking of the interface, the material was assumed to be isotropic. The response of the interface under tensile and shear stresses was assumed to be linear before any fracture occurred. Due to its special thin geometry, the interface element was assumed to crack only along the glue surface or perpendicular to it, as shown in Figure 3. Cracks perpendicular to or along the glue surface occurred as soon as the corresponding normal stress reached the tensile strength of the interface. After cracking, the stress and the elasticity modulus in the corresponding direction were set to zero. Numerically, it was set to $0.001 \mathrm{E}_{\mathrm{g}}$. The Poisson's ratio was neglected after crack. The shear modulus was reduced to 0.25 times the uncracked value [9]. The interface could also crack parallel to the glue surface under combined shear and normal stresses, which would follow a Mohr-Coulomb with a maximum tensile stress criterion given by

$$
\tau=c-\sigma \tan \phi
$$


where $\mathrm{c}$ is the cohesion for an interface. The wide cohesion range can be attributed to the variation in surface preparation and properties of the adhesive and the concrete. If the normal stress perpendicular to the glue surface was tensile at the instant of failure as predicted by Mohr-Coulomb's law, also referred to as the peeling stress, all stress components and elements of the material matrix were reduced to zero in its direction. In this case, the material matrix was updated to

$$
[D]_{L O}=\frac{E_{g}}{\left(1+v_{g}\right)\left(1-2 v_{g}\right)}\left[\begin{array}{cccccc}
1-v_{g} & v_{g} & 0 & 0 & 0 & 0 \\
v_{g} & 1-v_{g} & 0 & 0 & 0 & 0 \\
0 & 0 & 0 & 0 & 0 & 0 \\
0 & 0 & 0 & \frac{1-2 v_{g}}{2} & 0 & 0 \\
0 & 0 & 0 & 0 & 0 & 0 \\
0 & 0 & 0 & 0 & 0 & 0
\end{array}\right]
$$

However, if the normal stress perpendicular to the glue surface was compressive at the instant of failure as predicted by Mohr-Coulomb's law, then only the shear stress and the corresponding shear modulus were set to zero. In this case, the material matrix was updated to

$$
[D]_{L O}=\frac{E_{g}}{\left(1+v_{g}\right)\left(1-2 v_{g}\right)}\left[\begin{array}{cccccc}
1-v_{g} & v_{g} & v_{g} & 0 & 0 & 0 \\
v_{g} & 1-v_{g} & v_{g} & 0 & 0 & 0 \\
v_{g} & v_{g} & 1-v_{g} & 0 & 0 & 0 \\
0 & 0 & 0 & \frac{1-2 v_{g}}{2} & 0 & 0 \\
0 & 0 & 0 & 0 & 0 & 0 \\
0 & 0 & 0 & 0 & 0 & 0
\end{array}\right]
$$

If the crack was perpendicular to the glue surface, the material matrix with principal axes normal and parallel to the direction of the crack becomes

$$
[D]_{\max }=\left[\begin{array}{cccccc}
0 & 0 & 0 & 0 & 0 & 0 \\
& E_{g} & 0 & 0 & 0 & 0 \\
& & E_{g} & 0 & 0 & 0 \\
& \text { symmetric } & & 0.25 G_{g} & 0 & 0 \\
& & & & G_{g} & 0 \\
& & & & & 0.25 G_{g}
\end{array}\right]
$$

The material matrix, $[\mathrm{D}]_{\max }$, in the coordinate system of the crack must also be transformed into the form of the local coordinate system.

\section{B. Other Material Model}

Concrete consider the nonlinear behavior and potential cracking. The internal steel bar use plastic theory. The steel plate using the deformation theory of plastic are adopt. The details and material properties can be found in author's paper [10].

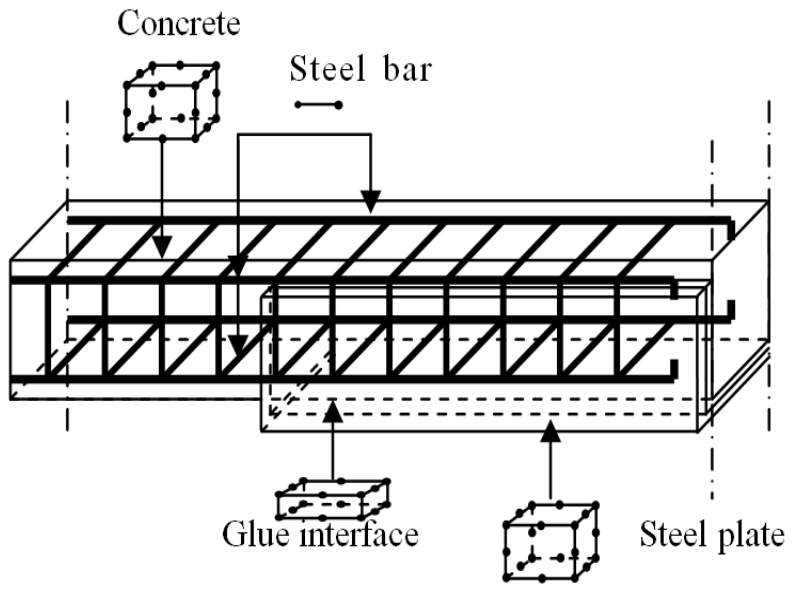

FIGURE II. FINITE ELEMENT MODEL.

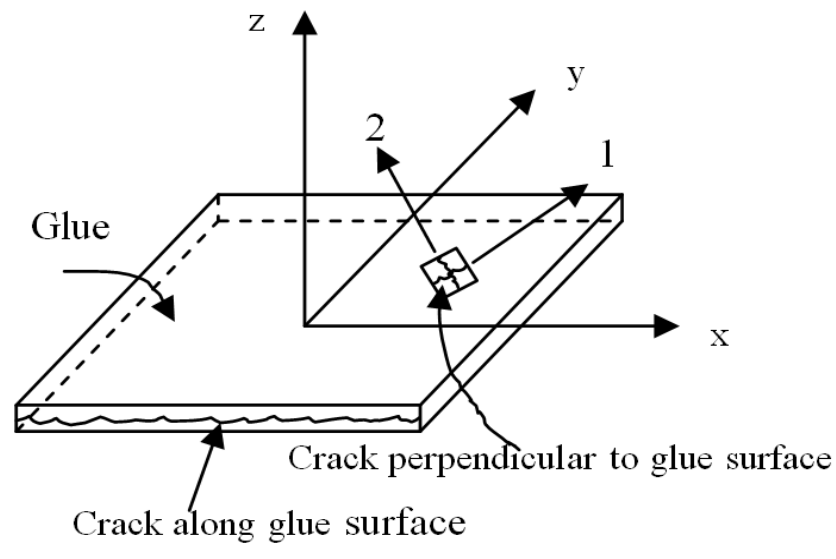

FIGURE III. TYPE OF GLUE CRACK.

\section{NUMERICAL EXAMPLE AND VERIFICATION}

\section{A. Verification of $3 D$ Interface Element}

The simply supported beam, as show in Figure 4, was considered in verifying the correctness of the thin interface three-dimensional element by comparison of analytic solution [11] and two-dimension finite element solution [8]. The material properties of this beam were assumed as follows: for concrete, Ec=27520 MPa, $v_{\mathrm{c}}=0.2$; for glue, $\mathrm{Eg}=294 \mathrm{MPa}$, $v_{\mathrm{g}}=0.16$; and for the plate, Es=200GPa, $v_{\mathrm{s}}=0.3$.

The interface stress distribution along the glue line of the beam is shown in Figure 5. Figure 5 shows the stress concentration in the plate curtailment, and shows the comparison of the finite element solution and Roberts's analytic solution, where close agreement is indicated. Hence, the $3 \mathrm{D}$ thin interface element qualified for the finite element analysis.

\section{B. Verification of RC Cap-Beams Strengthened by Plates}

Two of the cap-beams tested [12] were selected to verify the finite element model. The cap-beams are referred to as CB1 and CB3, and the experimental details and material properties are described as a reference.

Figure 6 shows comparisons between the numerical and 
experimental load-deflection curves, where the deflection is the one at the position of $250 \mathrm{~cm}$ measured from the center of the side of the cap-beam. Figure 7 shows comparisons between the numerical and experimental distribution of deflections along the side of the cap-beam under $\mathrm{P}=5884 \mathrm{kN}$. As shown in these figures, the load-deflection curve and distribution obtained from the finite element method agreed well with that from the experimental data. In Figure 8, the shadow regions represent a separation between the concrete and strengthening plates under the ultimate loading level. These regions represent that the values of the interface stress for sampling Gauss points were higher than those calculated by the Mohr-Coulomb fracture criterion. From Figure 6 and 8, it can be seen that although the cap-beam displayed partial separation in both the lateral and bottom sides, it still reached flexural strength, and the area of separation did not extend in the bottom for the cap beam strengthened using this method.

\section{CONCLUSIONS}

(1) The three-dimensional thin element for simulating the behavior of concrete / epoxy / steel plate interface has been verified by a comparison of the analytic solutions of Robert's formula and Ziraba's two-dimensional model.

(2) The interface element can predict the shear and normal stress concentration, and the separation after the peak shear and normal stress exceeded that obtained by MohrCoulomb with maximum tensile stress criterion

(3) The three-dimensional nonlinear finite element method can capture the essential behavior characteristics of RC structures strengthened by external steel plates up to failure.

\section{REFERENCES}

[1] R. N. Swamy, R. Jones, and A. Charif, "The Effect of External Plate Reinforcement on the Strengthening of Structurally Damaged RC Beams,” Struct. Eng., Vol. 67, No 3, pp. 45-56, 1989.

[2] R. N. Swamy, R. Jones, and J. W. Bloxham, "Structural Behaviour of Reinforced Concrete Beams Strengthened by Epoxy-Bonded Steel Plates,” Struct. Eng., Vol. 65A, No 2, pp. 59-68, 1987.

[3] M. Ryback, "Reinforcement of Bridge by Gluing of Reinforcing Steel," Mater. Struct., Vol. 16, No. 91, pp. 13-17, 1981.

[4] T. Iino, K. Otokawa, "Application of Epoxy Resins in Strengthening of Concrete structures," Proceeding Third International Congress on Polymers in Concrete, Koriyama, Japan, Vol. II pp. 997-1011, 1981.

[5] B. H. Oh, J. Y. Cho, and D. G. Park, "Failure behaviour and separation criterion for strengthened concrete members with steel plates”, J. Struc. Eng., Vol. 129, No. 9, , pp. 1191-1198, 2003.

[6] M. T. El-Mihilmy, and J. W. Tedesco , "Prediction of anchorage failure for reinforced concrete beams strengthened with fiber-reinforced polymer plates”, ACI Struct. J.,Vol. 98, No. 3, pp. 301-314, 2001.

[7] H. Saadatmanesh, and A. M. Malek, , "Design guidelines for flexural strengthening of RC beams with FRP plates”, J. Compos. Constr., Vol. 2, No. 4, pp. 158-164, 1998.

[8] W. S. Lin, and C. C. Kao, "Nonlinear finite element 2 D analysis for RC beams strengthened by epoxy bonded steel plates", Chin. J. Mech.-Ser. A, Vol. 19, No. 4, 409-419, 2003.

[9] Y. N. Ziraba, and M. H. Baluch, "Computational Model for Reinforced Concrete Beams Strengthened by Epoxy Bonded Steel Plates,” Finite Elem. Anal. Des.,Vol. 20, pp. 253-271, 1995.

[10] W. S. Lin, C. C. Kao, and I. C. Tsai, “3D Nonlinear Finite Element Analysis for Structures Strengthened by Steel Plates,” J. Chin. Inst. Civ.. Hydr. Eng., Vol. 16, No 3, pp. 465-475, 2004.
[11] T. M. Boberts, ”Approximate analysis of The Shear and Normal Stress Concentrations in the Adhesive Layer of the Plated RC Beams," Struct. Eng., Vol. 67, No 12, pp. 229-233, 1989.

[12] W. S. Lin, C. C. Kao, and I. C. Tsai, "Tests of Full Scale Cap-beams, “J. Chin. Inst. Civ.. Hydr. Eng., Vol. 13, No 3, pp. 175-180, 2001.

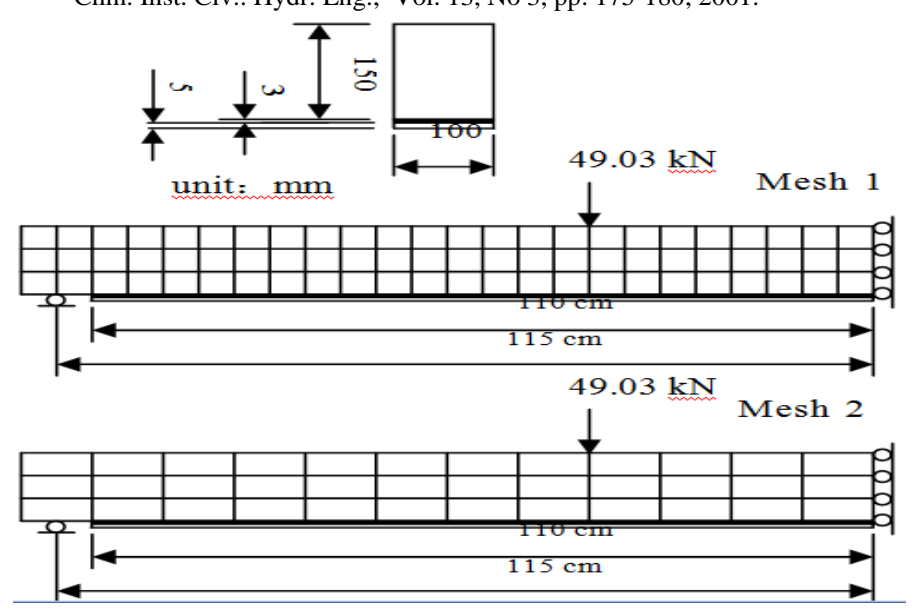

FIGURE IV. BEAM DIMENSION AND ANALYSIS MESH.

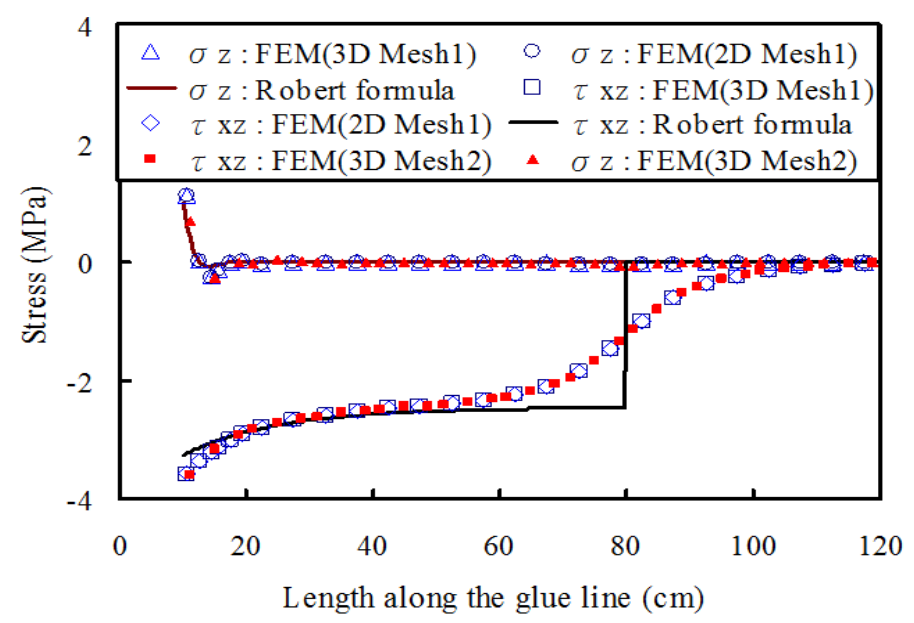

FIGURE V. STRESS DISTRIBUTION ALONG THE GLUE LINE.

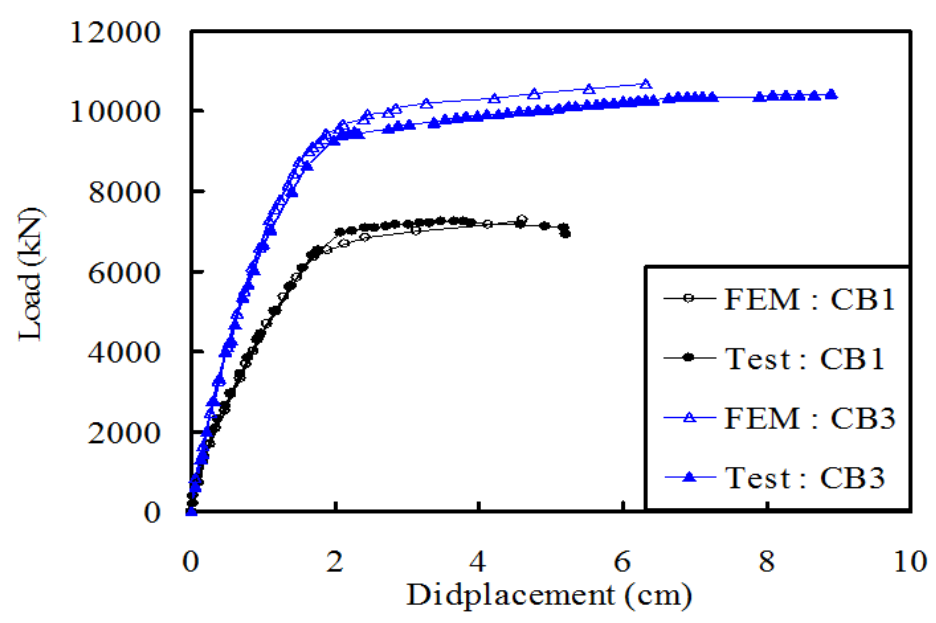

FIGURE VI. LOAD DEFLECTION CURVE ON DISTANCE 250 CM FORM CENTER OF CAP-BEAM. 


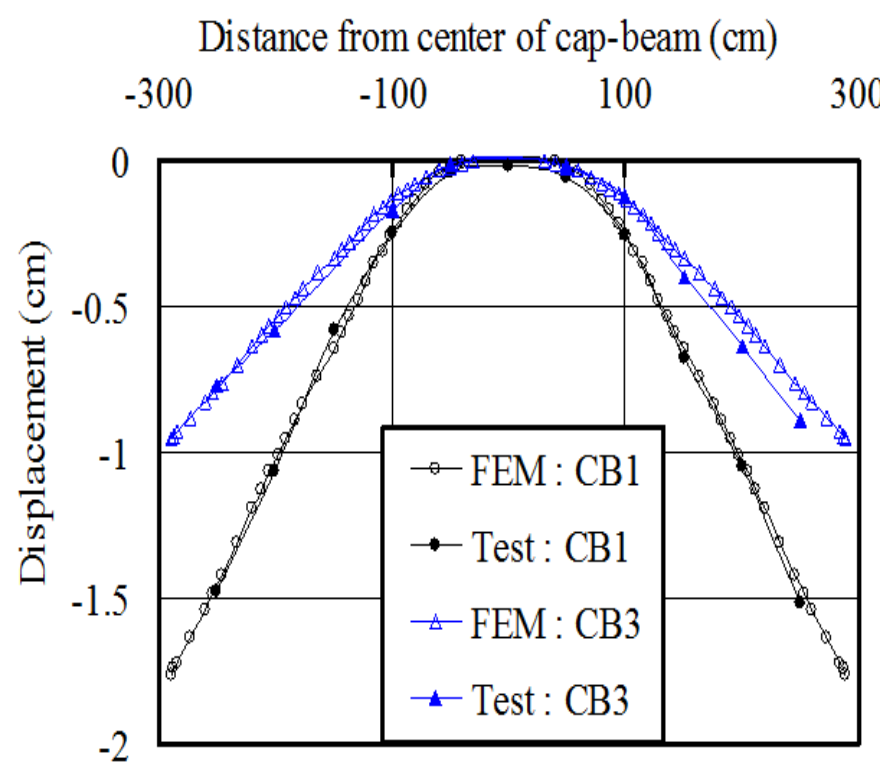

FIGURE VII. DISTRIBUTION OF DISPLACEMENT WHEN P=5884 KN.

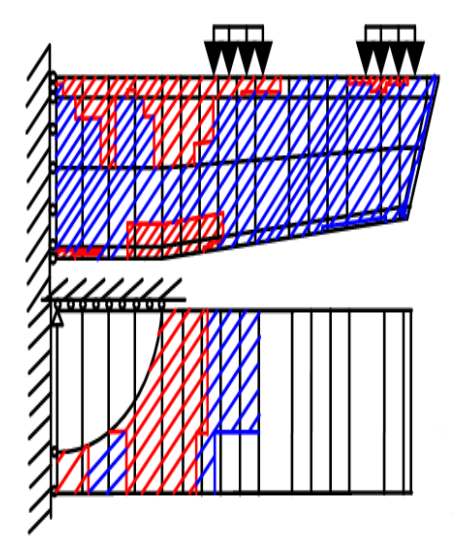

(a) FEM (quarter of cap beam)
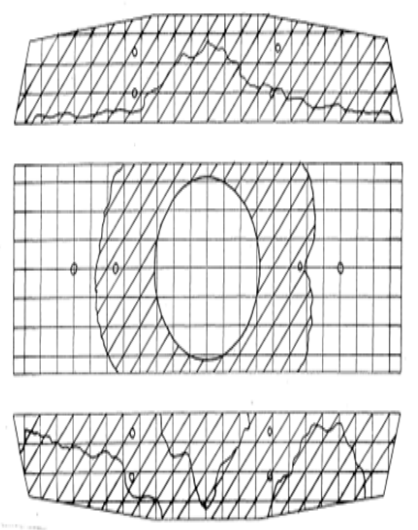

(b) Experiment

FIGURE VIII. SEPARATION OF CB3 UNDER ULTIMATE LOAD. 